\title{
Síndrome de Morel Lavallée
}

\author{
Morel Lavallée syndrome \\ Carlos Iván Andrade Aguilar,* Edgar Turrubiates Lucero,* Luis Gerardo Domínguez Gasca* \\ Citar como: Andrade ACl, Turrubiates LE, Domínguez GLG. Síndrome de Morel Lavallée. \\ Acta Med. 2021; 19 (1): 140-141. https://dx.doi.org/10.35366/98589
}

Paciente femenino de 49 años, sin antecedentes de importancia, que acude a urgencias por presentar dos horas antes de su arribo traumatismo directo sobre pierna derecha por automóvil, a la exploración: zona equimótica rodilla y cara anterointerna de pierna y tobillo, dolor intenso sobre cabeza de peroné, hipoestesia en territorio equimótico, al igual que en territorio cutáneo del nervio peroneo; sin datos de síndrome compartimental, pulsos y llenado capilar normales, con vendaje de Jones se hospitaliza y se solicitan radiografías (Figura 1) corroborando fractura de cabeza de peroné; al tercer día se presenta edema en pierna y presencia de flictenas, permaneciendo llenado capilar y pulsos presentes. Con el diagnóstico clínico de síndrome de Morel Lavallée se solicita resonancia magnética que lo confirma (Figura 2), la paciente presentó necrosis cutánea, que requirió de debridación y aseos quirúrgicos seriados, además de injerto de piel, reconstrucción del complejo posterolateral de rodilla con técnica de Larson modificado, liberación del nervio peroneo y rehabilitación prolongada.

El síndrome de Morel-Lavallée (SML) descrito en 1863 es una afección de los tejidos blandos; de observación más frecuente en el género femenino. Su fisiopatogenia implica traumatismo directo y/o tangencial con fuerzas de cizallamiento sobre tejidos blandos ocasionando la separación abrupta de la piel y el tejido celular subcutáneo respecto a la fascia muscular, lo que origina un espacio que se llena por líquido proveniente de la ruptura de arterias perforantes y de vasos linfáticos así como de tejido graso necrótico. ${ }^{1}$ Generalmente, la sintomatología

\footnotetext{
* Ortopedista, Cirugía articular. División de Cirugía del Hospital Ángeles León. León, Guanajuato México.
}

Correspondencia:

Dr. Luis Gerardo Domínguez Gasca

Correo electrónico: luisdom88@hotmail.com

Aceptado: 09-04-2020.

www.medigraphic.com/actamedica

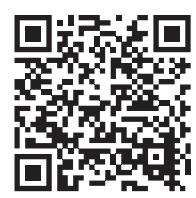

se manifiesta uno a varios días después del traumatismo inicial, por lo que puede pasar desapercibido y generar complicaciones como infección y necrosis cutánea; ello hace necesario un diagnóstico precoz y un tratamiento adecuados. $^{2}$ El diagnóstico clínico es confirmado con estudios de imagen, siendo la ecografía la más adecuada en etapa aguda, la imagen ecográfica habitual presenta presencia de líquido con aspecto fusiforme anecoico. En las imágenes de resonancia magnética se le clasifica en VI tipos, correspondiendo el tipo I a presencia de seroma, el tipo II a hematoma subagudo con presencia de metahemoglobina; el tipo III, a hematoma crónico organizado con hemosiderina, tejido de granulación tejido necrótico, fibrina y coágulos; el tipo IV, a laceración cerrada con ausencia de cápsula, el tipo $\mathrm{V}$, a lesión pseudonodular perifascial y; el tipo VI, a lesión con infección superpuesta y engrosamiento capsular. ${ }^{3}$
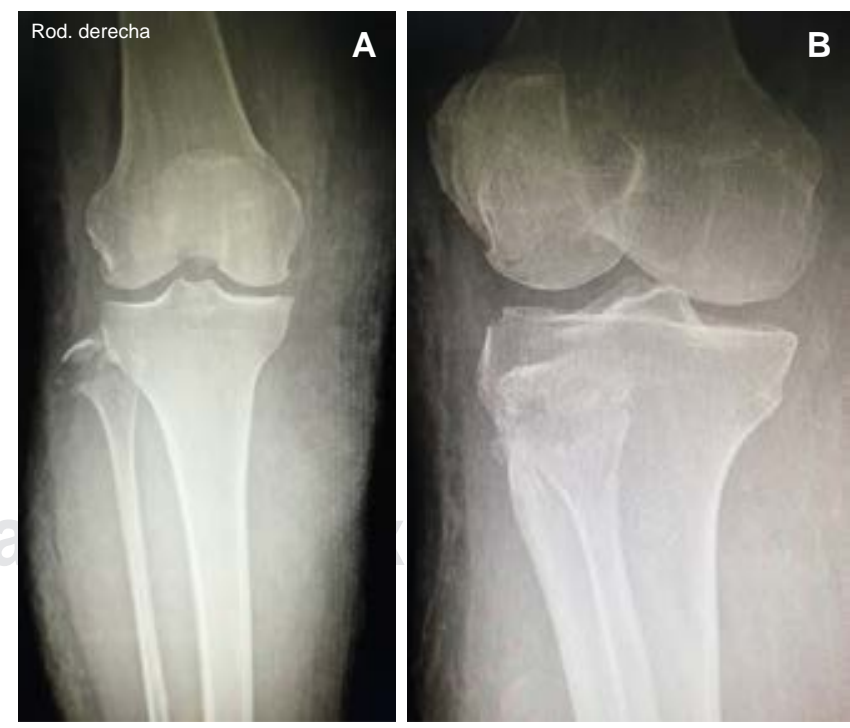

Figura 1: A y B) Radiografías simples de rodilla que muestran fractura de cabeza de peroné y edema de tejidos blandos en pierna derecha. 

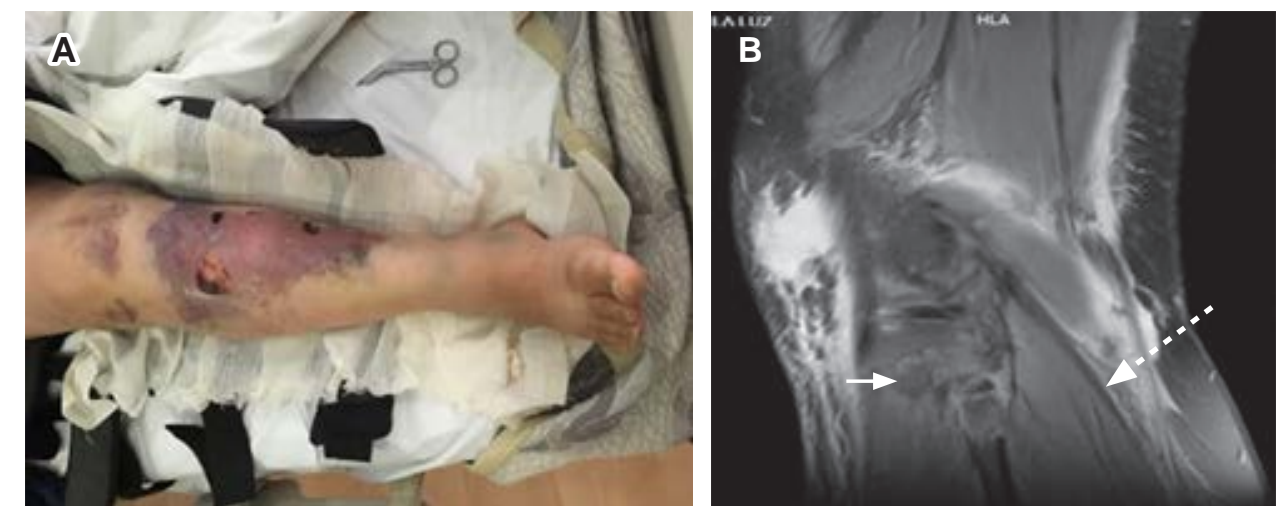

Figura 2:

A) Fotografía clínica que muestra equimosis en pierna

y presencia de flictenas y necrosis dérmica. B) Imagen de resonancia magnética en corte sagital que muestra edema y fractura de peroné.

C y D) Cortes axiales de pierna a diferente altura que muestran líquido en tejido celular subcutáneo (flechas).
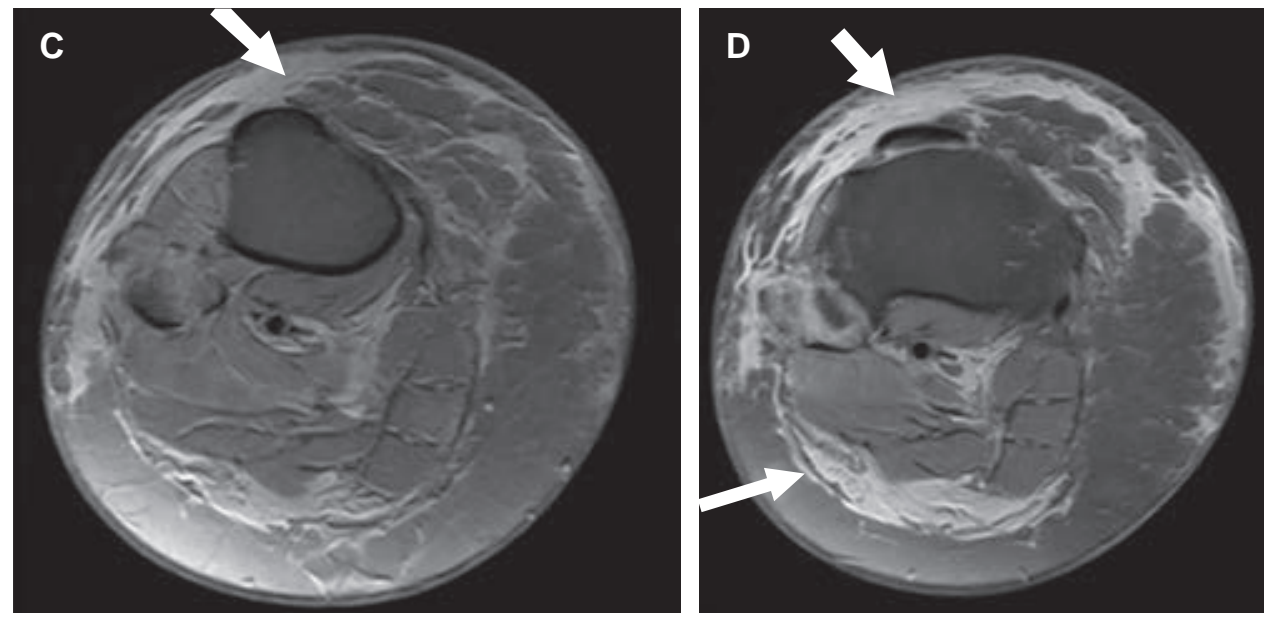

El tratamiento conservador, evitando traumatismos sobre la zona, con aplicación de vendaje de compresión (que debe mantenerse durante cuatro semanas, puede ser eficaz en los seromas de pequeño tamaño) y analgesia con antiinflamatorios no esteroideos, se consideran la primera línea de tratamiento en pequeñas lesiones agudas sin fracturas óseas acompañantes. ${ }^{4}$ El drenaje percutáneo se puede utilizar para tratar lesiones agudas más grandes que no se pueden resolver con tratamiento conservador de no ser así, debe procederse a drenaje o desbridamiento quirúrgico en los de mayor tamaño; se reserva la esclerosis con doxiciclina para las formas más rebeldes. Cuando el tratamiento conservador falla o cuando se aspiran más de $50 \mathrm{~mL}$ de líquido, está in- dicado el tratamiento quirúrgico que puede ser abierto o endoscópico. ${ }^{5}$

\section{REFERENCIAS}

1. Martínez CT, Arévalo PA, Pérez RL, Sobradillo CN, Urbano VC. Morel-Lavallée syndrome: a view from primary care. Med Gen Fam. 2018; 7 (5): 208-210. doi.org/10.24038/mgyf.2018.048.

2. Herreros SM, Albañil BM, Cabezudo PJ. Seroma de Morel-Lavallée. Rev Pediatr Aten Primaria. 2019; 21: 271-273.

3. Villagrán MJ, Díaz CM, Bueno HA. Lesión de Morel-Lavallée: diagnóstico y tratamiento con técnicas de imagen. Radiología. 2018; 60 (3): 230-236.

4. Riemer K, Haukenes O, Kozak A. Morel-Lavallée lesion. Tidsskr Nor Laegeforen. 2019; 139 (1). doi: 10.4045/tidsskr.18.0351.

5. Greenhill D, Haydel C. Rehman S. Management of the MorelLavallée lesion. Orthop Clin North Am. 2016; 47 (1): 115-125. doi. org/10.1016/j.ocl.2015.08.012. 